\title{
Moriré en Moscú con aguacero
}

\author{
I will die in Moscow with downpour
}

\begin{abstract}
VERÓNICA ProSKURNINA
Instituto Cervantes de Moscú · veronicap@list.ru

De padre cubano y madre rusa, nació en 1968 en Moscú. A los dos años se trasladó con su familia a Cuba, donde vivió hasta 1989. Cursó estudios en la escuela soviética de La Habana y más tarde estudió cuatro años en la Universidad de La Habana, en la facultad de Periodismo. En 1987 ganó el premio David con el libro de relatos Adolesciendo. En 1989 ingresó en el Instituto Gorki de Moscú, el que terminó en 1994. Actualmente trabaja en el Instituto Cervantes de Moscú, donde imparte clases de español, y en la agencia de noticias RIA Nóvosti en calidad de periodista y traductora.
\end{abstract}

\section{ENSAYO AUTOBIOGRÁFICO}

RECIBIDO: 28 DE ENERO DE 2015

ACEPTADO: 7 DE FEBRERO DE 2015

DOI: 10.7203/KAM.5.4579 
Mi pertenencia a una y otra cultura y mi nacionalidad es algo que me preocupa desde que tengo conciencia de mí misma. Si no me gusta bailar salsa, ¿se me puede considerar cubana? ¿Puedo ser rusa y detestar el vodka? ¿Y por qué no puedo ser simplemente una terrícola, sin pertenecer a ninguna nacionalidad concreta?

Hay dos países y dos culturas que han determinado mi carácter y mi vida y me han marcado profundamente. Estos dos países, además, son completamente diferentes: los dos polos opuestos que he tenido que ensamblar en mi mundo interior. Uno de ellos es frío y muy grande, el más grande del mundo y, para colmo, el más frío. El otro es pequeño, es una isla en el trópico, "el país del eterno verano”.

El primero es Rusia, donde nací en 1968, y el otro es Cuba, donde viví más de 20 años y que abandoné en 1989. En cuanto a la forma de ser, no hay personas que se parezcan menos que los habitantes de estos países. Los cubanos son alegres, abiertos, vivos; les gusta divertirse, bailar. Los rusos son muy cerrados, cuando no conocen a una persona son incapaces de entrar en contacto con ella, son poco predecibles en sus acciones, tienen cambios muy repentinos de humor, pueden pasar rápidamente de la tristeza más infinita a la alegría sin aparente causa, y son dados a la depresión.

Dicen que el clima determina el carácter de la gente y por eso los habitantes del sur son más comunicativos y alegres que los del norte. Para mí, que tengo ambas culturas en la sangre, resulta verdaderamente problemático combinar el carácter cerrado de los rusos con la jovialidad de los cubanos. Por eso soy alegre, pero al mismo tiempo tímida. Cuando vivía en Cuba, me gustaba bailar, pero me daba vergüenza que me miraran. Siento simpatía por la gente que me rodea, pero me resulta difícil hablar con un desconocido y durante mi infancia no tuve demasiados amigos.

Como viví la primera parte de mi vida en Cuba, hasta los 21 años, prácticamente no conocía la Rusia real, pero me consideraba una rusa (no de físico, pues soy morena, pero sí de carácter). Nada más alejado de la realidad: el carácter de los rusos es como lo describe Dostoyevski, muchos son como Raskolnikov y Sonia Marmeladova al mismo tiempo, o como los hermanos Karamazov. Venir a Rusia significó para mí descubrir que en realidad era cubana.

En mi infancia, las pocas veces que vine de vacaciones no logré conocer a la gente ni ver el país; iba por uno o dos meses a casa de mi abuela, veía a mis tíos, a mis primos, visitaba la Plaza Roja, algún teatro y ya. Tenía una imagen de Rusia idealizada y muy literaria, la conocía a través de la literatura del siglo XIX y de inicios del siglo XX. ¡Tanto más grande fue el choque con la vida real de ésta, mi segunda patria!

El primer choque con la realidad rusa ocurrió a los 14 años, cuando decidí quedarme un año para conocer por fin Rusia. No me afectaría en mis estudios, pues en Cuba estaba estudiando en una escuela rusa, y podía vivir con una hermana de mi madre que estaba soltera y con mi abuelo. Mi madre siempre 
estuvo en contra de ese plan, no sólo porque no quería dejarme sola, sino además porque la adolescencia es de por sí un período difícil, no es el momento más apropiado para vivir sin los padres en un país desconocido, pero mi padre insistió. Él pensaba que un año de vida en Rusia me bastaría para no querer nunca vivir en ese país.

Ahora, con la experiencia de los años y después de haber tenido mis propios hijos, me asombra mucho la decisión tomada por mis padres. Mi padre era psicólogo y creo que el hecho de tener un psicólogo en casa complica mucho las cosas, pues resulta como en el dicho "En casa del herrero, cuchillo de palo”. Sin embargo, él casi logró quitarme las ganas de vivir en Rusia, ya que mi vida durante ese año fue muy difícil.

Para empezar, mi madre no era de Moscú, era de la periferia, y en la Unión Soviética la vida en las ciudades de provincia difería mucho de la vida en la capital (y sigue siendo muy diferente hoy en día), el abastecimiento era pésimo, muchos edificio permanecían sin repararse. En la escuela donde estudié, en mi grupo había niños que ya eran alcohólicos empedernidos (¡de 14 años!) y dos niñas se prostituían sin que a nadie le preocupara ese hecho.

Cuando me enfermé y me ingresaron en el hospital infantil de esa ciudad, descubrí que aquel lugar era como una filial de la cárcel: los niños estaban ingresados sin los padres, no los dejaban salir a pasear e incluso ¡los obligaban a limpiar el suelo! A mí aquello me pareció increíble, que a los pacientes, a los niños, los obligaran a limpiar y me negué a hacerlo rotundamente. Entonces me prohibieron verme con mi tía (que venía todas las tardes al hospital y me traía de comer) y recibir los paquetes de los visitantes. Además de apropiarse de lo que ella traía, llegaron a llamarme "judía” y "armenia” (como soy morena, no les parecía suficientemente rusa, pero no lograban definir mi procedencia y trataban de ofenderme de esa forma).

Fue un año muy difícil, el año en que, además, murió Brezhnev, 1982. Realmente pude ver con mis 14 años qué terrible era aquel sistema, para mí la Unión Soviética se convirtió también en el "imperio del mal”, aunque ahora sé que eso también era una mentira, otro cliché.

Después de esas experiencias dejé de creer en el socialismo y en todas las ideas que intentaban meternos en la cabeza en la escuela rusa y en los medios de prensa cubanos. Descubrí que el socialismo verdadero, el ruso, se asemejaba a un sistema de cárceles, en el cual la escuela era una cárcel, el hospital era otra, el ejército era una cárcel con un régimen a veces peor que en una cárcel real y el grado de libertad dependía del lugar donde te encontraras, pero la única libertad permitida era la libertad interna.

Ahora aquí en Rusia las cosas han cambiado bastante. Precisamente la posibilidad de cambios y de decir lo que se piensa fue lo que me hizo volver a este país, a pesar de la impresión que me había llevado 
cuando era adolescente. Mi padre no pudo prever los cambios que ocurrieron en el mundo: la "perestroika”, la caída del muro de Berlín, y mucho menos que él mismo se vería obligado a venir a Rusia y quedarse en ella para siempre...

La vida en Rusia fue y sigue siendo para mí un reto, es una vida complicada, dura, pero que te hace crecer y madurar. Por eso puedo dividir mi vida en dos partes, y a cada una de ellas va a corresponder un país. Mi infancia y adolescencia pasaron en Cuba, y Cuba es para mí el maravilloso país de la niñez, ese país al que todos quisiéramos volver un día. El país de nunca-jamás, el de Peter Pan. Rusia es la madurez y es un examen permanente, es el inexplicable mundo de Las almas muertas de Gógol; un coche que tres caballos tiran por una estepa nevada, cada año al finalizar el invierno piensas: ¡he sobrevivido un año más!, y a la vez te sientes orgullosa de haberlo logrado.

Mis primeros años de vida fueron muy felices. Amo profundamente la naturaleza y puedo admirar durante horas un paisaje o ante una flor, y la naturaleza de Cuba es inigualable. Además viví en un barrio que era un inmenso jardín. Es el barrio Cubancán, uno de los barrios residenciales de La Habana, donde antes de 1959 vivía la gente rica y ahora es habitado por los profesores y científicos y la "nueva" gente rica - los funcionarios y los diplomáticos. En ese barrio se encuentra el Instituto Médico "Victoria de Girón” (actualmente es una universidad médica), donde trabajaba mi padre, y por eso fue que nos dieron casa en un lugar tan privilegiado.

La casa era muy grande, color rosa, y la compartíamos con otra familia de profesores de Girón. Delante de la casa crecía un enorme árbol de flamboyán, sus ramas cubrían toda la parte derecha del tejado y sus flores rojas eran como llamas de fuego cada vez que florecía. Me resultaba muy intrigante el hecho de que en cada flor hubiera, además de los pétalos rojos, un pétalo multicolor, de fondo blanco, con franjas de todos los colores del arco iris. Para mí era un pétalo mágico, un pétalo que se puede lanzar al viento y pedir un deseo, como en un cuento ruso que había leído una vez: La flor de los siete pétalos. Aunque el flamboyán tuviera sólo un pétalo mágico en cada flor, en esa época había suficientes flores en mi árbol para que se cumplieran todos mis deseos.

Había otro árbol con flores al final del jardín, eran flores blancas, grandes y poseían un olor muy agradable. Las llamábamos margaritas, pero desconozco el nombre real, creo que las margaritas no crecen en árboles. Ese era el árbol dónde jugábamos a las casas y yo era como el personaje de Pedro Luis Ferrer en su Romance de la niña mala: la niña que trepaba a los árboles, a los tejados, que tiraba piedras y se peleaba con otros niños.

También venían a nuestro jardín de vez en cuando los zun-zunes, unos pájaros muy pequeños y muy hermosos que se llaman también colibríes. El zun-zun es el pájaro más pequeño del mundo, se 
alimenta del néctar de las flores como una mariposa. Además, cuando vuela, mueve tan rápido las alas que éstas no se ven, sólo se ve un cuerpecito verde y brillante suspendido en el aire, y un pico muy largo que se sumerge en las flores por un instante y luego el pájaro desaparece como por arte de magia.

En el mundo de mi infancia casi no habitaban personas, las personas mayores existían en una dimensión paralela, y los otros niños, al parecer, no tenían mucha entrada en ese jardín multicolor. Tampoco recuerdo que jugara a las muñecas, nunca me gustaron mucho. Los juegos con otros niños los descubrí años más tarde, cuando empecé a ir a la escuela y mi visión del mundo ya había cambiado.

Todo lo que me rodeaba seguía siendo armonioso y limpio, pero yo era otra. Me sentía fuera de la naturaleza. Una vez, al atardecer, mirando las nubes blancas que pasaban encima de mí, pensé que querría ser como ellas, blanca, limpia, y sentí para mis adentros que aquello era imposible. ¿Y por qué no puedo ser limpia como una de esas nubes blancas, si no he hecho nada malo?- pensé para mis adentros. No encontraba la respuesta. Fue un sentimiento de asombro que recuerdo hasta hoy, como de haber descubierto una verdad que es imposible explicar, pero que presientes como muy importante. Años más tarde, cuando estudié un poco la Biblia, el pecado original, eso me explicó por qué me sentía sucia y no podía ser blanca como una nube, pero el recuerdo de aquella tarde quedó para siempre grabado en mi mente como el descubrimiento de mi mundo interior que no dependía de la naturaleza que me rodeaba.

Los niños de mi barrio me trataban como si fuera diferente a ellos, nuestra amistad era algo superficial, creo que porque yo era bastante seria y además era la única niña que había estado fuera de Cuba, que había hecho un viaje en avión, que había visto el mundo. Un poco para molestarme, me preguntaban: “¿pero has visto la nieve?”, y sí que la había visto, de pequeña, a los 4 años, cuando viví en Rusia un año entero. Y eso les daba envidia porque en Cuba todos sueñan con ver la nieve y jugar con ella. Les parece que la nieve es una maravilla. En cambio aquí en Rusia, cuando te encuentras casi 6 meses rodeada de nieve, realmente quisieras un poco de sol y de calor.

A mí más que la nieve siempre me ha gustado el mar, el mar cálido que también formaba parte de mi mundo infantil. Los primeros meses en Moscú me resultaba difícil concebir que no tuviera mar, cuando iba en un coche me daba cuenta de que había estado buscándolo con la mirada y me parecía que debía estar cerca, que sólo bastaba con subir por aquella calle para que se abriera el horizonte a las olas y el olor salobre me invadiera, pero todo resultaba vano. Era raro no tener el mar al alcance de la mirada. Una ciudad sin mar es para mí una ciudad cerrada, como un laberinto sin salida.

Mis primeros años en Cuba habían pasado en un barrio de la costa habanera, en Mayanima, y esa sensación de espacio enorme, de libertad que te da la visión del océano, es la visión de felicidad que tengo hasta el día de hoy. El mar es la felicidad y cuando puedo pasarme una temporada en la playa, lo 
hago sin falta. He estado muchas veces en el mar Negro, en el Báltico, en el mar Rojo (en Egipto) y en el mar Mediterráneo (en España).

En la playa de Mayanima viví casi un año y recuerdo que había cientos de cangrejos que por las tardes salían a pasear y a buscar alimento, así que la arena parecía desplazarse junto a ellos. Era la playa de los cangrejos. Después dejó de serlo, creo que se los comieron todos durante los años 70. Había un cangrejo que era fumador, pues se robaba las colillas de mi padre y se las llevaba a su cueva, y una mariposa borracha que se posaba en su vaso de cerveza y se bebía los restos. (Claro que era mi padre el que se había bebido el vaso, pero le gustaba bromear y yo me lo creía).

En esa época empezaron las preguntas tontas de las personas mayores. Siempre me resultó muy difícil responder a preguntas tontas. Hay gente que hace preguntas porque no sabe cómo hablar con un niño. La pregunta más tonta era la de mi nacionalidad: ¿Tú eres rusa o cubana? Como si eso dependiera de mí. Como si de eso dependiera algo. Si digo que soy rusa o que soy cubana, eso no cambia nada dentro de mí. Normalmente la gente pregunta estas cosas como si la respuesta fuera evidente. Es como cuando a un niño le preguntan a quién quiere más, a su mamá o a su papá.

Es un jueguito de las personas mayores para ver sufrir a los niños, pues si alguien debe decidir entre dos seres tan importantes como lo son los padres, realmente se ve en un apuro. Igualmente a la hora de escoger a qué nación pertenecer, si tus padres provienen de países diferentes. No sabría por cuál decidirme, más cuando se trata de dos culturas tan singulares como la rusa y la cubana. ¿Qué prefiero, la literatura rusa del siglo 19 o los carnavales en los pueblos pequeños de Oriente, donde todo el mundo sale a bailar a las calles? Pues me quedo con los dos, porque los dos me gustan. Elegir entre Rusia y Cuba sería como elegir entre mi padre y mi madre, entre mi padre cubano y mi madre rusa. Escoger a uno sería traicionar al otro, por eso prefiero decir que soy las dos cosas a la vez.

Soy mitad rusa y mitad cubana, como aquellos animales míticos que eran hombre y animal a la vez, soy "polovina”, como se les llama en Cuba a los descendientes de rusos y cubanos, soy "mitad", mitad persona y mitad animal o cualquier otra cosa.

En Mayanima vivimos "prestados” en casa de un colega de mi padre hasta que cumplí los cuatro años y los recuerdos de la mariposa y del cangrejo son anteriores a esa edad. Al principio mi madre no trabajaba, la recuerdo lavando a mano en un lavadero y yo metida en un cubo de agua donde cabía completa, así que era bien pequeña. Cuando paseábamos por nuestro barrio, situado bastante cerca del mar, la gente nos miraba con mucha curiosidad y hacía comentarios en voz alta, como mi madre no hablaba todavía español, podía decir lo que quisiera. Pero yo sí que los entendía. Los niños que vivían allí me gritaban casi siempre "la rusita”, "allí va la rusita”, aunque físicamente de rusa no tengo nada, como 
he dicho ya. A mí me molestaba mucho que me llamaran así, por eso se me ocurrió la siguiente respuesta: "Yo no soy ninguna rusita. ¡Me llamo Verónica Pérez Cubana!” En realidad me llamo Verónica Pérez Kónina y mi segundo apellido, “Konina”, a la edad de cuatro años me sonaba casi igual a "cubana”. Era curioso que precisamente se tratara de mi apellido ruso, el apellido de mi madre.

Cuando vivía en Cuba nunca me gustó sentirme rusa entre cubanos; a diferencia de mi madre, que nunca quiso dejar de ser "extranjera". Siempre me he sentido atraída por la gente "de a pie”, por la gente de la calle, a pesar de que mis padre eran profesores universitarios. Tal vez porque la vivienda que nos dieron se encontraba en un barrio residencial de antiguos "burgueses" y en mi barrio sólo vivían profesores, deseaba salir de ese oasis “pequeño burgués” de Cubanacán y enterarme de cómo vivía la gente "normal", sentía mucha curiosidad por saber cómo vivían los que no tenían padres universitarios.

Mi padre era de la parte oriental de la isla, de un pueblo muy pequeño llamado Palmarito de Cauto, cerca de Santiago, y como había estudiado en Rusia psicología, en su pueblo no tenía nada qué hacer, ni siquiera tenían un hospital, mucho menos una consulta psiquiátrica... Por eso tuvo que buscar trabajo en la capital.

Así que mis padres también eran en la Habana personas venidas de fuera, mi madre con su estatus de extranjera, a la que todos envidiaban por tener más posibilidades de "conseguir" alimentos, sobre todo, en un país donde la comida siempre fue y sigue siendo un problema. Mi padre, "oriental”, de esos que habían venido a conquistar la capital, fue una persona que se formó gracias a la revolución, pues pudo ir a estudiar gratis una carrera universitaria a otro país, pudo obtener una vivienda en La Habana, realizarse como profesional. Nada de eso hubiera podido hacer sin la revolución, ya que su padre era un simple obrero azucarero y lo más que soñaba para su hijo es que fuera un tecnólogo del central. El hecho de que personas como mi padre se hubieran visto obligadas a dejar su país demuestra que algo anda mal, si no fuera por el período especial, él nunca se hubiera ido. ¡Y qué duro es emigrar con 50 años, cuando ya has vivido la mayor parte de tu vida!

Así que siempre he sido una persona venida de fuera, en Rusia porque vine de Cuba, y en Cuba por mi madre rusa y mi padre oriental. He sido una emigrante interna, porque he tenido mi propia visión de las cosas. Puedo decir que siempre me he sentido un poco extranjera, "demasiado rusa para ser cubana y demasiado cubana para ser rusa”, parafraseando a Lourdes Casal, poeta norteamericana de origen cubano. Pero he tratado también de traspasar esa frontera, de ser como todos. Mi lema ha sido como en la canción de Celia Cruz: “Ay, no hay que llorar, que la vida es un carnaval, y las penas se van cantando...”

En cada cultura hay algo importante que aporta ese país a la cultura universal, y en Cuba es precisamente ese júbilo, esa capacidad de alegrarse en cualquier circunstancia. En Rusia la gente no tiene esa capacidad de alegrarse, son personas más amargadas, más cerradas. Pero tienen una mentalidad 
más universal, más filosófica. Puedo decir que viviendo en Cuba siempre añoré Rusia, y en Rusia vivo añorando mi Cuba.

Una vez vi en la televisión rusa una entrevista con Andy García, actor norteamericano de origen cubano, que dijo que para él su padre había sido ese pedacito de patria que había sacado de Cuba. No recuerdo exactamente sus palabras, ese era el sentido general, pero para mí aquello sonó como si lo hubiera dicho yo misma. Yo también tuve la suerte de poder sacar de Cuba a mi padre, que vivió en Moscú casi 10 años, y cuando murió, en el año 2004, sentí como si hubiera perdido ese pedazo de patria que él representaba para mí. Fue algo repentino, nadie se lo esperaba, y en aquel entonces me dolía tanto pensar que se quedaría para siempre en esta tierra tan fría e inhóspita, que hubiera dado mucho por poder trasladar su cuerpo a la tierra donde había nacido. El siempre quiso volver a Cuba, aunque fuera de visita, y nunca quiso estar enterrado en Rusia, quedar aquí para siempre.

El día que lo enterramos era un día lluvioso de marzo, el cielo estaba gris y caía una nieve dura como de escarcha, la fosa estaba llena de agua helada y sucia. Los enterradores habían disimulado un poco el charco en el fondo de la fosa con ramas de pino, las únicas ramas verdes en esa temporada, pero me resultaba tan doloroso ver ese hueco negro en la tierra que me daban ganas de gritar. Por eso no pude ver el momento en que bajaron el féretro y empezaron a tirarle la tierra encima. Sólo miré cuando estaba ya formada una loma bastante grande de tierra húmeda. Era esa humedad tan típica de Moscú que te cala hasta los huesos, todos estábamos congelados ya, y qué angustioso me resultaba pensar que sus huesos se quedarían para siempre en ese lugar tan frío. ¿O es que después de muerto eso ya no le importaba?

“Moriré en París con aguacero, un día del que tengo ya el recuerdo...”, me vino a la mente. Vallejo fue el poeta preferido de mi padre, y ese poema siempre le gustó recitarlo de memoria... Fue en Rusia, no en París, con una lluvia helada, con escarcha. En mayo, cuando se secó todo y los árboles se vistieron de verde, fuimos con mi madre y mis hijos a visitar su tumba por primera vez después del entierro. Es que en primavera hay tanto barro que hubiera sido imposible llegar hasta su tumba. En realidad, no sabíamos muy bien qué hacer allí. Limpiar un poco ese montículo de tierra, tirar a la basura los restos de los ramos y coronas, y sentarnos allí en un banco fue lo poco que pudimos hacer en su memoria. No teníamos experiencia de visitar a alguien en el cementerio. Llevábamos unas velas que enterramos en la tierra y encendimos. El viento trataba de apagarlas y nos pareció muy alentador que saliera un lagarto y se quedara largo rato tomando el sol en la tumba, sin notar nuestra presencia. Eso nos pareció una buena señal, como un mensaje del más allá, pero más alentador todavía nos resultó ¡descubrir no muy lejos un monumento con un nombre español! Por supuesto que aquel nombre estaba escrito con caracteres cirílicos, pero no cabía la menor duda, había un tal Antonio Ruiz enterrado muy cerca de mi padre. El hombre había muerto hacía unos 20 años y, según las fechas grabadas en el monumento, podría tratarse 
de uno de esos "niños de la guerra" españoles que fueron evacuados a Rusia a finales de los años $30 \mathrm{y}$ luego no pudieron volver a su tierra. Y si no se trataba un niño de la guerra, qué más da, era alguien de origen hispano, mi padre ya no estaría tan solo, había alguien más de su misma lengua y de su misma cultura que estaba allí enterrado. Fue una gran alegría para mi madre y para mí hacer ese descubrimiento.

Como dijo María Zambrano: “mi patria es el idioma”, y mi padre tendría allí su pedazo de patria, como lo es para mí ahora en Moscú el Instituto Cervantes, donde trabajo hace casi 12 años, ese pedazo de patria hispana que me ayuda a sobrevivir.

Lo más difícil como emigrante no es tanto el idioma, pues el idioma ruso es como mi segunda lengua y a veces, incluso la primera, sino el hecho de no poder entender a la gente. Si no has vivido en ese país, no has visto las mismas películas que han visto todos, no has escuchado las mismas canciones, no has ido a la misma guardería y a la misma escuela, no tienes mucho en común con la gente y no la entiendes. En Cuba yo podía leer en los rostros de la gente, no hacían falta las palabras para saber qué tipo de personas eran, de qué estrato social, incluso de qué barrio de La Habana. La forma de vestir, el peinado, los gestos todo formaba parte de un código completamente descifrable.

A veces los estudiantes del Cervantes me hacen preguntas sobre Cuba que siempre trato de evadir. En mi vida cotidiana no hay nada que pueda recordarme mi país y es algo premeditado, pues trato de evitar los recuerdos. Hablar de Cuba me hace sufrir. Sólo los sueños son aquello que no puedo controlar, veo mi país cuando duermo y luego me despierto muy triste. Por suerte, esto ocurre cada vez con menos frecuencia.

Hablo de Cuba con los alumnos cuando no me queda más remedio. Entre la gente mayor rusa hay muchos que todavía simpatizan con Fidel y la revolución, y si se enteran de que soy cubana, expresan su simpatía por Cuba y por su curso político. Una de estas alumnas ya un poco mayores me contó un día que había visto de lejos a Fidel durante su última visita a Moscú y me confesó la admiración que sentía por él. Además, empezó a comparar la situación en Rusia, donde, en su opinión, todo estaba mal, con Cuba, donde todo estaba bien.

"Los chinos tienen un refrán que dice que lo peor para una persona es vivir en una época de cambios"- me dijo. "Y Rusia hace muchos años que está en período de cambios, parece que los cambios nunca van a terminar. Por eso estamos tan mal. Afortunados los cubanos, que han podido evitar los cambios".

Entonces no pude contenerme más y le dije: “Los cubanos tenemos muchas esperanzas de llegar a ver también esos cambios y vivirlos en carne propia. Por lo menos yo espero poder ver esos cambios con mis propios ojos." 
Si mi padre no pudo llegar a verlos, por lo menos yo los veré por él.

Espero que ese día todos los cubanos que viven en Cuba, los que están fuera, los “mitad” cubanos y los "cubanos $100 \%$ " estemos juntos y hagamos todo lo posible para que nuestro país tenga un futuro feliz. 